\title{
ATENDIMENTO EDUCACIONAL PARA ALUNOS COM NECESSIDADES EDUCATIVAS ESPECIAIS NA ESPANHA
}

\author{
EDUCATIONAL ASSISTANCE FOR STUDENTS WITH SPECIAL \\ EDUCATIONAL NEEDS IN SPAIN
}

\author{
Maria Odete de MATTOS ${ }^{\mathrm{i}}$ \\ José Luís BIZELLIii
}

RESUMO: A construção do artigo está baseada no contraste entre análise documental e observação direta do atendimento educacional para estudantes com necessidades educativas especiais na Espanha, país que tem sido reconhecido como referência na reflexão crítica e na organização de modelos de atendimento para a escola inclusiva. Partindo-se de breve exposição sobre o Sistema Educacional espanhol, o trabalho recupera aspectos relevantes sobre a ordem jurídico-institucional que estrutura a inclusão na escola, analisando os recursos humanos disponibilizados para cumprir as funções especializadas e os aspectos referentes à gestão escolar, tanto no que se refere ao planejamento como à operação prática das rotinas de atendimento.

PALAVRAS-CHAVE: Atendimento educacional. Necessidades educativas especiais.

ABSTRACT: The construction of the article is based on the contrast between document analysis and direct observation of educational services for students with special educational needs in Spain, a country that has been recognized as a reference in critical reflection and organization of care models for inclusive school. Starting from a brief presentation on the Spanish Educational System, work retrieves relevant aspects of the legal and institutional order that structures the inclusion in school, analyzing the human resources available to meet the specialized functions and aspects relating to school management, both as regards planning as to the practical operation of the service routines.

KEYWORDS: Educational services. Special educational needs.

\section{Introdução}

Há um desafio hoje colocado para a Escola em Ibero-América no que diz respeito às possibilidades e aos limites de oferecer um ambiente educativo propício para o desenvolvimento de todos os cidadãos ${ }^{\mathrm{iii}}$. Atenção maior merece o assunto quando se trata de pensar na inclusão de pessoas com deficiência (BIZELLI; SEBASTIAN HEREDERO; RIBEIRO, 2015; BIZELLI; SOUZA, 2014b). Assim, entender as 
peculiaridades históricas das trajetórias de construção da escola inclusiva em cada país ibero-americano é uma tarefa que demanda atenção e urgência.

A atenção específica dos autores deste artigo está voltada ao entendimento e à reflexão sobre a organização do atendimento educacional especializado na Espanha, país que é referência em práticas escolares inclusivas e que mantém trajetória histórica consolidada no sentido de atender as recomendações mundiais da Unesco (1994) para o bom funcionamento da escola inclusiva.

Enquanto método de análise, o trabalho adotou as técnicas qualitativas para estudar os documentos oficiais e a legislação que tanto a Espanha como o estado de Castilla La Mancha têm desenvolvido nos últimos anos. A partir de observação direta viabilizada por estágio realizado em um conjunto de escolas durante o ano de 2014 - foi possível completar a interpretação aqui exposta.

A Espanha, com população de quarenta e sete milhões de habitantes, é um país descentralizado em todos os níveis. Em questões de Educação, por exemplo, as dezessete Comunidades Autônomas (CCAA), equivalentes aos estados brasileiros, têm toda a responsabilidade sobre as regulamentações educativas. Mesmo que a rede de ensino não seja municipal, o atendimento está bem próximo do cidadão e permite ações de accountability que garantem a eficiência, já que todas as CCAA se subdividem em províncias ou territórios, cujo tamanho facilita o controle exercido pelos cidadãos. À União - ou seja, ao estado central espanhol - cabe ditar as leis gerais que marcam os pontos comuns de todas as CCAA e responsabilizar-se por supervisionar e avaliar os resultados das políticas traçadas.

No atendimento educacional, como se diz em Espanha (1995), todas as escolas se encontram preparadas para receber qualquer tipo de criança ou adolescente. Para tanto, existem planos estratégicos, professores treinados, recursos orçamentários adequados e equipe de orientação pedagógica dentro de cada escola com função de acompanhar e avaliar os processos educacionais adotados. Embora sejam raros, em alguns casos há educandos que frequentam a escola especial.

$\mathrm{O}$ atendimento especial é planejado para cada indivíduo, sendo referenciado para a sua sala de aula. É o professor regente da sala que gerencia as atividades que serão desenvolvidas por esta criança ou adolescente. Assim, toda a gestão do processo se dá, normalmente, dentro da própria sala, salvo nas raras oportunidades quando, em função de características específicas, há necessidade de atendimento especializado oferecido por professor de educação especial ou por fonoaudiólogo. 


\section{O Sistema Educativo da Espanha}

Na Espanha, em 1990, depois de vários anos de caminhada democrática, de um intenso processo de debate e discussão, foi aprovada - por consenso estabelecido entre todas as forças políticas da nação - a "Ley Orgánica General del Sistema Educativo LOGSE” (ESPANHA, 1990), a qual marcou avanços na trajetória educativa do país e posição importante no debate internacional sobre a temática. Entre outras questões de relevância a lei estabeleceu que a duração do ensino básico obrigatório e gratuito seria de dez anos e que o currículo seria aberto, compreensivo e flexível para permitir a inclusão escolar.

É no contexto desta legislação que se apresenta a educação especial em sua forma de trabalhar para entender os sujeitos com necessidades educativas especiais. Em 1995, o Real Decreto 696/1995 de ordenación educativa de los alumnos con necesidades educativas especiales (ESPANHA, 1995) passa a regulamentar todo o processo de organização de recursos e de indicações pedagógicas para vertebrar o modelo de escola inclusiva derivado da Declaração de Salamanca de 1994 (UNESCO, 1994)..

A partir de 1995, portanto, inicia-se a implantação do modelo que hoje se encontra totalmente operativo em todas as escolas espanholas, oferecendo as condições materiais necessárias para que crianças e adolescentes com deficiência evoluam em seu processo educativo, com a ressalva já apontada sobre a existência das escolas de Educação Especial que atendem as multideficiências ou deficiências severas.

A estrutura jurídico-institucional espanhola sobre Educação completou-se, mais recentemente, com três Leis Gerais: a Ley de Calidad de la Educación - LOCE promulgada em 2002 (ESPANHA, 2002), que pouco alterou concretamente os rumos práticos da vida escolar, a Ley Orgánica de Educación - LOE (ESPANHA, 2006) que efetivamente ajustou e atualizou a LOGSE e a Ley Orgánica para la Mejora de la Calidad Educativa - LOMCE (ESPANHA, 2013), marco de reformulação da prática educativa espanhola, já que traz uma nova proposta alicerçada em currículo mais fechado e diferenciado segundo as capacidades dos educandos e de seus resultados escolares. Quanto a respostas para a diversidade, o texto também incorpora a mesma ideia de criar uma pluralidade maior de opções segundo as diferenças apresentadas pelos sujeitos individuais ${ }^{\mathrm{iv}}$. 
Abaixo apresentamos o organograma referente ao Sistema Educacional espanhol. Como é possível observar na figura (1), os três níveis da educação - a saber: Infantil, Fundamental e Superior - estabelecem entre si um conjunto de articulações, dando organicidade ao sistema.

Figura 1 Sistema Educativo Espanhol de 2013.

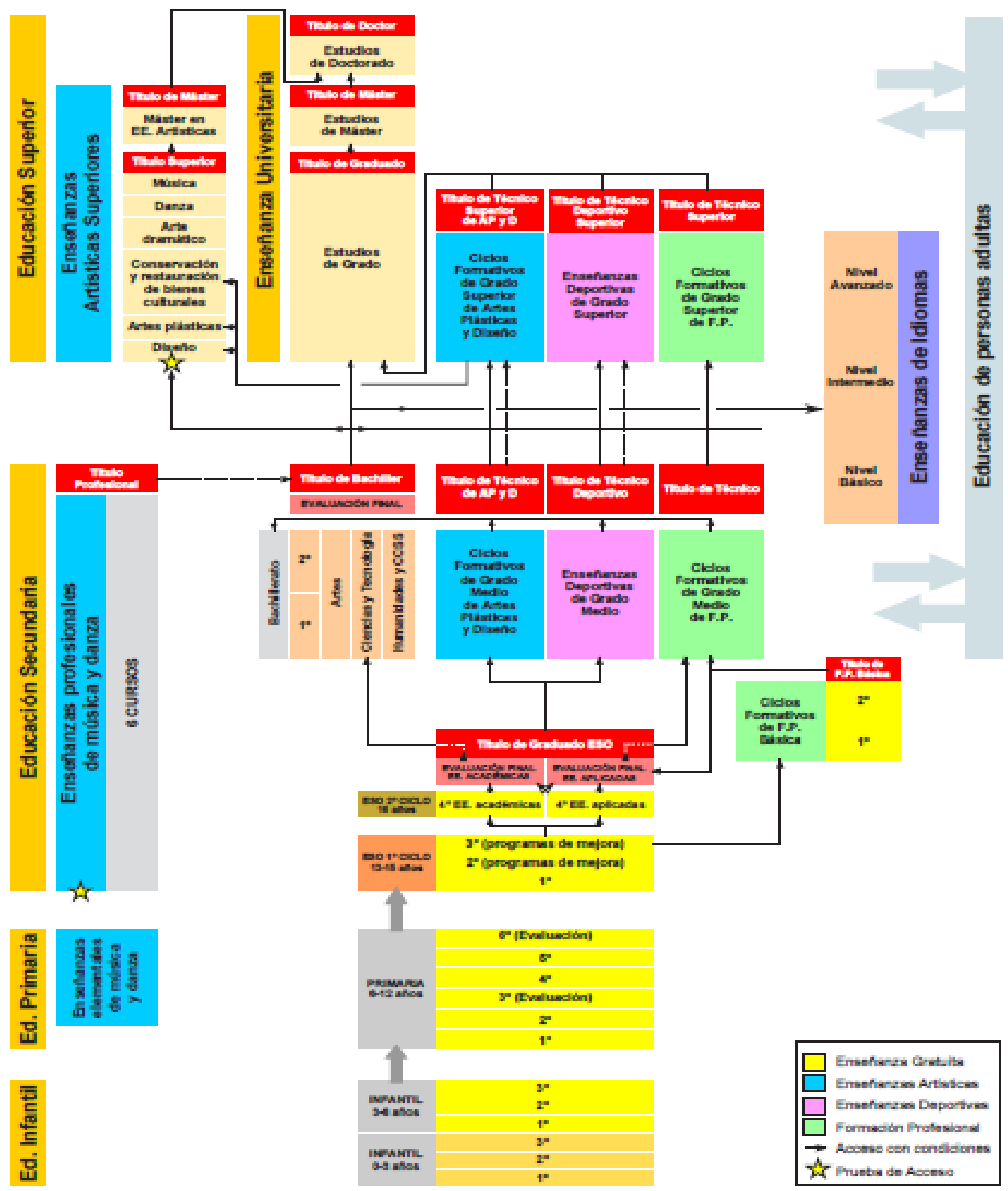

Fonte: Gobierno de España 


\section{O professorado na Espanha}

O professor que atua na educação infantil espanhola é graduado em Magistério: Educação Infantil e só atua nessa etapa educacional. Já aquele que atua na educação primária tem formação polivalente para o grau de Magistério, sendo que, algumas vezes, também recebe formação especializada em Língua Estrangeira, Música ou Educação Física. Quando é responsável por uma turma é denominado Tutor, assumindo toda parte de apoio didático-burocrático da turma, ou seja, ele acompanha e orienta o seu grupo de educandos, tanto individual como coletivamente, estabelecendo os relacionamentos com as famílias ${ }^{\mathrm{v}}$ (ESPANHA, 1990).

Para dar resposta à diversidade existem os professores de apoio, que são de dois tipos: o Professor de Pedagogia Terapêutica, que é o especialista dedicado a promover o ensino para crianças e adolescentes com necessidades educativas especiais associadas a deficiências ou a transtornos graves de conduta e o Professor de Audição $e$ Linguagem, que é um especialista dedicado a, por um lado, promover e desenvolver competências linguísticas, e, por outro lado, superar sintomas de patologias relativas a linguagem oral e escrita (ESPANHA, 1995).

Todos os educadores formados até o ano de 2010 em Magistério já possuem especialidade na própria formação inicial. Mais recentemente, a formação para lidar com necessidades especiais vem sendo oferecida na pós-graduação. Em algumas CCAA existem ainda os Professores de Educação Compensatória (ESPANHA, 1995), os quais atuam em escolas para atender especificamente aos alunos de minorias étnicas, compensando as carências culturais encontradas; suprindo a ambiência de sujeitos que estão pela primeira vez no ambiente escolar; e auxiliando a aprendizagem da língua espanhola para imigrantes que ainda não possuem esse domínio.

Já os professores do ensino secundário têm graduação em suas especialidades, atuando em áreas específicas de conhecimento (ESPANHA, 1990). As graduações não contemplam a formação específica para atuar em sala de aula, o que exige a complementação dos estudos - com duração de um ano - através de Máster en formación del profesorado de secundaria, curso que os habilita a ministrar aula no ensino secundário (ESPANHA, 2006). 


\section{Tipos de centros educativos na Espanha.}

$\mathrm{Na}$ Espanha, para a formação dos alunos do ensino fundamental, existem três tipos de escola: públicas, privadas e concertadas. As escolas públicas são financiadas pelas CCAA, enquanto as privadas são financiadas pelas famílias dos educandos. As concertadas são de natureza privada, mas recebem subvenções da Administração Central, atendendo, assim, aqueles que, inicialmente, não poderiam frequentar uma escola pública. Duas situações explicam as escolas concertadas: a inexistência de escolas públicas em algumas regiões; e a tradição histórica espanhola cuja origem data do início do século passado com forte influência e ação educacional da igreja.

A evolução jurídico-institucional que sofreu a educação espanhola - entre a última década do século passado e os dias atuais (ESPANHA, 1990, 2013) - consolidou a seguinte organização:

- $\quad$ O primeiro ciclo da educação infantil (0-3 anos) é atendido em creches municipais ou particulares pois não é obrigatório;

- $\quad$ O segundo ciclo da educação infantil (3-6) é atendido nas mesmas escolas que oferecem o ensino básico (6-12), as quais quando públicas se chamam Colegios de Educación Infantil y Primaria (CEIP) e quando particulares ou concertadas chamam-se genericamente Escolas.

- $\quad$ O ensino médio compreende educandos da Enseñanza Secundaria Obligatória (12-16), do Bachillerato (16-17) e de Formación Profesional (16-21), etapas educativas cumpridas em instituições; que quando são públicas são chamadas de Institutos de Educação Secundária.

Completam o sistema as Escolas de Educação Especial que atendem as crianças e adolescentes com deficiências severas; o Centro de Educación de Personas Adultas voltado ao mesmo atendimento para pessoas com idades superiores a 18 anos; as Escuelas Oficiales de Idiomas para o ensino de línguas; as Escolas de Artes, nas quais se pode cursar o Bachillerato de Artes ou seguir os estudos para a Formação Profissional sobre Artes.

\section{Organização educacional na Espanha.}

A Constituição Espanhola de 1978 reconhece e garante, em seu artigo 2º direito à autonomia das nacionalidades e regiões, bem como a solidariedade entre elas. 
Assim, definiu-se o novo modelo de Estado descentralizado espanhol, estabelecendo uma divisão de competências entre a Administração do Estado central e as CCAA algo similar à configuração da União e os Estados em outros países. Cada comunidade autônoma adéqua seu escopo jurídico-institucional à legislação nacional de acordo com suas necessidades e seu contexto (ESPANHA, 1978).

O estado espanhol organiza todas as suas ações educativas através do Ministério de Educação, o qual de sua sede em Madri atua através das Direções Gerais - órgãos de gestão diferenciados situados nas CCAA, cuja função é mediar as demandas específicas de cada região e realizar um sistema periódico de reuniões conjuntas de todos os Conselheiros de Educação de todas as CCAA. Na prática, o Estado espanhol não trabalha diretamente com as escolas, pois só tem competências em duas cidades autônomas -Ceuta e Melilla - e nas escolas de titularidade espanhola no exterior.

Em $1^{\circ}$ de janeiro do ano 2000, o poder central delegou às CCAA a total responsabilidade da área de educação como previa a Constituição (ESPANHA, 1978) e a LOGSE (ESPANHA, 1990). As administrações locais, portanto, são responsáveis, como visto anteriormente, apenas pelo $1^{\circ}$ ciclo da educação infantil - ciclo 0-3. Cabe ao Estado, em sua maior parte, as reponsabilidades de caráter executivo e normativo, ou seja, as ações que visam sobretudo a possibilidade de transferência de qualquer estudante entre CCAA; os aspectos que visam o regulamento comum para salvaguardar a unidade substancial do sistema e garantir condições de igualdade de todos em seus direitos educativos ${ }^{\mathrm{vi}}$; a avaliação geral do sistema e dos níveis de aprendizado dos educandos. Com o objetivo de garantir a realização das ações atribuídas em matéria de ensino, a administração estatal conta com órgão executivo - a Alta Inspección de Educación - e com o Consejo Escolar del Estado.

Às estruturas das CCAA correspondem competências executivas administrativas e normativas que auxiliem no desenvolvimento das normas estatais básicas; na regulação de aspectos não básicos do sistema educativo; no ajustamento do currículo; e em ajudas e subsídios aos estudantes. O órgão responsável é a "Consejería de Educación”, o qual se estrutura da mesma forma que o Ministério, tendo à frente o Conselho e Direções Gerais nas diferentes áreas da administração. Para uma melhor estruturação e maior proximidade com a população em cada província ${ }^{\text {vii }}$, há "Delegaciones Provinciales" em todas essas áreas e à frente da mesma há um responsável denominado "Delegado". 
Diante do objeto de interesse particular deste artigo na estrutura educacional espanhola, o Ministério, as Consejerias de Educación e as Delegaciones Provinciales possuem um departamento específico de atenção à diversidade - incluindo a educação especial - o qual é o encarregado da gestão de recursos, da implantação e do acompanhamento das políticas e, também, da formação continuada dos professores. Outras estruturas institucionais funcionam como apoio às administrações, tais como os órgãos de Inspección Educativa Provincial ou Centros de Formación Permanente del Profesorado.

As escolas têm autonomia para a gestão organizativa, pedagógica e econômica de seus espaços educativos, o que permite até a criação de currículo adaptado às condições dos educandos de uma região específica ou possibilita até a obtenção de recursos próprios, mesmo quando públicas (SEBASTIÁN HEREDERO, 2014).

\section{Atendimento educacional para a diversidade na Espanha}

Embora na Espanha exista uma trajetória de atendimento educacional consolidado para a diversidade, a legislação atual - LOMCE - com relação à Atenção à Diversidade, favoreceu a autonomia dos centros para "Organizar de maneira flexível o ensino e estabelecer medidas de atenção à diversidade" e para a consecução deste fim contemplou, por exemplo, medida como: "Realizar adaptações do currículo e integrar matérias; fazer agrupamentos flexíveis e adotar medidas de apoio em grupos comuns" (ESPANHA, 2013, art. 45).

Como já foi descrito, cada uma das CCAA tem autonomia para criar seus próprios sistemas e estratégias os quais venham a implementar o mínimo legal estabelecido na legislação nacional a ser cumprida.

Assim, de acordo com a legislação (ESPANHA, 1995), os estudantes se organizam em dois grupos de atendimento: Alunos com Necessidades Educativas que requerem de Apoio Educativo Especializado - ACNEAE -; e educandos que requerem atenção educativa diferente da comum, ou seja, aqueles que apresentam necessidades educativas especiais ou dificuldades específicas de aprendizagem: TDAH, altas habilidades ou foram incorporados tardiamente no sistema escolar. Tais necessidades devem ser verificadas pelos profissionais de orientação, constando em um Informe de evaluación psicopedagógica que é feito na própria escola, entre especialistas em 
orientação ou o orientador (Psicólogos, Pedagogos ou Psicopedagogos) e os ACNEAE, ou seja, aqueles que requerem, em um período de sua escolarização ou ao longo dela, determinados apoios e atenções educativas específicas devido à sua deficiência ou a transtornos graves de conduta.

O orientador, o professor de Pedagogia Terapêutica e o Professor de Audição e Linguagem é que assumem a responsabilidade de desenvolver o Plan de Atención a la Diversidad, ou seja, são eles que traçam a estratégia de organização e funcionamento de uma escola inclusiva (SEBASTIÁN HEREDERO, 2014). A partir do plano específico os professores tutores vão buscar outros apoios na programação- que permitam o desenvolvimento do educando, desenvolvimento este que será avaliado através dos resultados obtidos com as medidas de reforço e com as adaptações curriculares realizadas. É o tutor também que irá assessorar o professorado na aquisição e na elaboração de materiais específicos de acesso ao currículo e colaborar nos processos de assessoria e formação para as famílias.

O professor de Pedagogia Terapêutica é o especialista dedicado a promover o ensino especificamente com os ACNEE, ou seja, com aqueles que apresentam condições de superdotação, deficiência psíquica, sensorial ou motora, deficiências múltiplas e transtornos graves de conduta que tenham adaptações curriculares significativas. Incluem-se nesse quadro os que apresentam algum tipo de dificuldade de aprendizagem. É também atribuição do professor de Pedagogia Terapêutica dar subsídios aos professores no desenvolvimento de adequações necessárias ao universo de estudantes definido acima.

O professor de Audição e Linguagem (AL) é especialista dedicado a promover e desenvolver competências linguísticas, bem como em melhorar patologias relativas à linguagem oral e escrita. Destaca-se ainda que esse professor pode realizar intervenções prioritariamente no último curso da educação infantil e no primeiro ciclo da educação primaria para resolver problemas gerais relacionados com as dificuldades da fala.

O professorado de apoio ao programa de compensação educativa atua, fundamentalmente, no ensino da língua espanhola para imigrantes e em atividades que ajudem a equalizar os déficits culturais em minorias étnicas ${ }^{\text {viii }}$.

Algumas escolas têm outros profissionais técnicos (PT) trabalhando nesta equipe em função das necessidades dos educandos que frequentam o espaço escolar: os auxiliares técnicos educativos são profissionais que não pertencem à área da educação, não possuem, portanto, formação específica, mas atuam - através de uma formação 
básica - na atenção a crianças e adolescentes com necessidades educativas especiais que carecem de autonomia devido à deficiência física ou psíquica; os fisioterapeutas dão atendimento específico dentro das escolas; e os auxiliares técnicos sanitários profissionais graduados em enfermagem - exercem suas funções nos centros educativos com prévia solicitação da gestão escolar.

A forma de atuar do PT é diferente segundo cada CCAA e cada escola, porém existem algumas características comuns, já que trabalha dentro da própria sala de aula com o ACNEE desenvolvendo a adequação curricular preparada conjuntamente com o professor regente. As atividades acontecem de forma coordenada, em alguns dias e horários na semana, os quais são fixados com o orientador segundo as NEE envolvidas no atendimento e o tamanho do grupo. É normal que outros professores não especialistas deem atenção ao ACNEE em outros horários, completando as ações coordenadas que estão planejadas na adequação curricular de cada educando.

O atendimento pode ser prévio, simultâneo ou a posteriori aos conteúdos e trabalhos a serem desenvolvidos em sala de aula. Já o professor de AL atua de forma normal e individual fora da sala de aula, atendendo às dificuldades específicas de cada estudante. Como foi dito, é normal que ele trabalhe na prevenção de dificuldades nos primeiros anos da educação infantil e primária num atendimento coletivo junto com o professor regente.

Muitas escolas desenvolvem - paralelamente a todo o trabalho especializado e de apoios individualizados - estratégias que melhoram as possibilidades de inclusão concreta do ACNEE, implantando atividades de aprendizagens cooperativas, trabalhos em equipe, estratégias de ensino entre iguais, etc.; ou mesmo, incorporando as famílias, em determinados momentos, para ajudar a construção do espaço educativo da sala de aula. Assim, o ambiente escolar é colaborativo sob a coordenação da Direção e da Orientação da Escola, criando condições para a aprendizagem de todos.

\section{Considerações finais}

Uma vez analisado o modelo espanhol de organização e de atendimento educacional especializado, é interessante, de forma muito concisa, marcar - para o fechamento a este artigo - algumas ideias que poderiam ser úteis à discussão do modelo 
educacional brasileiro, visando melhor resposta sistêmica à aprendizagem dos educandos com deficiência que frequentam a escola que aqui se faz.

Primordial é organizar toda a Escola para poder dar resposta às necessidades de qualquer tipo de cidadão através de projeto estratégico de atendimento, o qual permita organizar recursos e formas de atuação, evitando a improvisação e dando segurança à equipe que trabalha na Escola, como um todo, e aos professores, de forma particular.

Fortalece a gestão escolar poder contar com um quadro habilitado de profissionais que possam atuar em laudos diagnósticos, principalmente se esses profissionais estiverem articulados em equipes técnicas, das quais a coordenação de atendimento para crianças e adolescentes com deficiência ou com dificuldades específicas seja membro efetivo.

Finalmente, é fundamental sublinhar a importância da atitude pedagógica dos professores dado que, no caso espanhol, o professor regente da sala é quem atende - de forma quase continuada - os estudantes com deficiência, auxiliando no desenvolvimento do plano individualizado. O seu trabalho é reconhecido tanto pelo professor de educação especial (PT), quanto pelo eventual fonoaudiólogo (AL), atores educativos que estão dentro das próprias escolas para complementar o atendimento ali oferecido.

\section{Referências}

BIZELLI, J. L.; HEREDERO, E. S.; RIBEIRO, P. R. M. (Org.). Inclusão e aprendizagem: desafios para a escola em Ibero-América (versão eletrônica). São Paulo: Cultura Acadêmica, 2015.

BIZELLI, J. L.; SOUZA, C. B. G. (Org.). Faces da Escola em Ibero-América. São Paulo: Cultura Acadêmica, 2014a.

BIZELli, J. L.; SOUZA, C. B. G. (Org.). Caminhos para a Escola Inclusiva. São Paulo: Cultura Acadêmica, 2014b.

ESPAÑA. Constitución Española. Madrid: Ministerio de la Presidencia. 1978. Disponível em: <http://www.boe.es/buscar/doc.php?id=BOE-A-1978-31229>. Acesso em: 12 out. 2015.

Ley Orgánica 1/1990, de 3 de octubre, de Ordenación General del Sistema Educativo. Madrid: Ministerio de la Presidencia. 1990. Disponível em:< https://www.boe.es/boe/dias/1990/10/04/pdfs/A28927-28942.pdf >. Acesso em: 15 de out. 2015 
Real Decreto 696/1995, de 28 de abril, de Ordenación de la Educación de los alumnos con necesidades educativas especiales. Madrid: Ministerio de la Presidencia. 1995. Disponível em: <https://www.boe.es/boe/dias/1995/06/02/pdfs/A1617916185.pdf. >. Acesso em: 10 de out. 2015.

Ley Orgánica 2/2006, de 3 de mayo, de Educación. Madrid: Ministerio de Educación, Cultura y Deporte. 2006. Disponível em: <http://www.mepsyd.es/mecd/atencion/educacion>. Acesso em 15 de outubro 2014.

LOMCE. Ley Orgánica 8/2013 para la Mejora de la Calidad Educativa. Madrid: Ministerio de Educación, Cultura y Deporte. 2013. Disponível em: <http://www.boe.es/boe/dias/2013/12/10/pdfs/BOE-A-2013-12886.pdf $\geq$ Acesso em 12 outubro 2015.

JABONERO, M.; MARTIN BRIS, M.; MARTINEZ ARIAS, A.; BIZELLI, J. L. (Org). Miradas diversas de la educación en Iberoamérica (versão eletrônica). 2ª ed. revisada e ampliada. Alcalá de Henares, Espanha: Servicio de Publicaciones de la Universidad de Alcalá, 2015.

SEBASTIAN HEREDERO, E. Organización de los servicios de apoyo para la atención a la diversidad en España: el caso de la Comunidad Autónoma de Castilla-La Mancha. IN: GIROTO, C. et al. Servicios de apoyo en educación especial: una mirada desde diferentes realidades. 2014. Universidad de Alcalá, Alcalá de Henares, 2014.

UNESCO.. Informe final da Conferência Mundial sobre Necessidades Educativas Especiais: Acesso e Qualidade, Salamanca, España, Ministerio de Educación, Cultura y Deporte .1994.

\section{Como referenciar este artigo}

MATTOS, Maria Odete de MATTOS.; BIZELLI, José Luís. Atendimento educacional para alunos com necessidades educativas especiais na Espanha. Revista IberoAmericana de Estudos em Educação, v. 11, n. esp. 2, p.1059-1071, 2016. Disponível em: 〈https://dx.doi.org/10.21723/riaee.v11.esp2.p1059-1071>. E-ISSN: 1982-5587.

\section{Sobre os autores}

${ }^{\text {i }}$ Mestranda em Educação Escolar. UNESP - Universidade Estadual Paulista. Faculdade de Ciências e Letras - Pós-graduação em Educação Escolar. Araraquara - SP - Brasil. 14800-901 mom.t.t@hotmail.com

ii Livre Docente (janeiro/2013) em Gestão de Políticas Públicas da Faculdade de Ciências e Letras UNESP, Campus de Araraquara, e está credenciado nos Programas de Pós-Graduação em Televisão Digital: informação e conhecimento (FAAC-UNESP, Bauru) e Educação Escolar (FCLAr-UNESP, Araraquara). Fez seu Pós-doutorado no Departamento de Ciencias de la Educación, da Universidad de Alcalá de Henares (UAH), Espanha (fevereiro a julho/2013), sendo um dos responsáveis pelo convênio 
sobre Educação entre a UNESP e a UAH. Foi Diretor da Faculdade de Ciências e Letras Unesp Araraquara e Presidente de seu Laboratório Editorial, durante o quadriênio 2009-2012. Araraquara, São Paulo, Brasil. Lattes: http://lattes.cnpq.br/3751287338655685>. Orcid <http://orcid.org/0000-0002-66341444>. E-mail: bizelli@fclar.unesp.br

\section{Notas:}

iii Um exemplo deste esforço vem sendo realizado pelo Grupo de investigação Cervantes (JABONERO; MARTIN BRIS; MARTINEZ ARIAS; BIZELLI; 2015; BIZELLI; SOUZA, 2014a) e pela própria Revista Ibero-Americana de Estudos em Educação.

iv Esta lei - por conta da falta de consenso na sua aprovação - é muito criticada. Especialistas apontam que existe alta probabilidade de que aconteça sua revogação com uma possível mudança de governo.

${ }^{v}$ Esta atividade também é exercida pelos professores da educação infantil (Espanha, 1990).

vi Entre eles a definição dos conteúdos curriculares mínimos ou básicos, as políticas de formação de professores e as políticas que garantam a qualidade da educação e das instituições educativas.

vii Território menor de organização administrativa e com diferente número em cada CCAA.

viii Como os ciganos, por exemplo. 